\title{
Educação familiar em linguagem infantil: contribuições do grupo focal
}

\author{
Grace Cristina Ferreira-Donati* \\ Débora Deliberato**
}

\section{Resumo}

$\mathrm{Na}$ área das Ciências Humanas, o Grupo Focal vem sendo utilizado como método para identificar percepções de diferentes grupos sociais, nas mais diversas temáticas. O objetivo do presente trabalho é apresentar as contribuições do grupo focal utilizado com mães de crianças com atrasos globais do desenvolvimento, em uma pesquisa que visou elaborar e adequar fascículos de orientação familiar em linguagem. $\mathrm{O}$ grupo focal foi constituído por quatro mães, a pesquisadora, que assumiu o papel de moderadora, e uma observadora, responsável, principalmente, por fazer o registro de comportamentos não verbais das participantes. No primeiro encontro foram dadas orientaçóes quanto ao objetivo das reunióes, o compromisso com a emissão de opinióes a respeito das características de formato e conteúdo dos fascículos, e quanto às funçóes da observadora e da moderadora. Foram realizadas oito reuniôes presenciais, quinzenalmente, ao longo de quatro meses. Os relatos verbais das constituintes do grupo foram registrados por meio de gravações de áudio, transcritos e organizados para posterior análise. O grupo focal se mostrou como procedimento adequado para envolver os pais num exercício reflexivo a respeito do desenvolvimento da comunicação e para definir os conteúdos e o formato de orientaçóes escritas para a população-alvo. Os resultados indicaram que a elaboração dos fascículos, em parceria com as famílias, oportunizou aos pais ampliar a participação no desenvolvimento da linguagem de seus filhos. Além disso, evidenciou-se que a interação entre os participantes, nos moldes de um grupo focal, configurou-se em fator desencadeador para a identificação de aspectos comuns no plano intersubjetivo.

Palavras-chave: Educação Especial; Grupo focal; Educação familiar.

* Doutora em Educação pela Universidade Estadual Paulista Júlio de Mesquita Filho, Marília, São Paulo, Brasil.

** Professora doutora na Universidade Estadual Paulista Júlio de Mesquita Filho, Marília, São Paulo, Brasil. 


\section{Family education in child language: contributions of the focus group}

\section{Abstract}

The Focus Group has been used in the area of Humanities as a method to identify perceptions of different social groups, in the most diverse themes. The objective of this work is to present the contributions from the focus group used with mothers of children with global development delays in a research that aimed to develop and to tailor fascicles of family counseling to language. The focus group was composed of four mothers, the researcher, who assumed the role of moderator, and an observer, mainly responsible for registration of non-verbal behaviors of the participants. In the first reunion, guidance was given on the purpose of the meetings; the commitment to the issue of opinions regarding the features of the format and content of the volumes; and as to the functions of the observer and moderator. Eight face-to-face meetings were held fortnightly over four months. Verbal reports of the constituents of the Group were registered through audio recordings, transcribed and arranged for further analysis. The focus group showed appropriate procedure to involve parents in a reflective exercise concerning the development of communication and to define the content and format of guidelines written for the target population. The results indicated that the preparation of installments, in partnership with families, made it possible for parents to expand participation in the language development of their children. In addition, it was evident the interaction between the participants, as a focal group, set up in the triggering factor for identifying common aspects in the inter-subjective plan.

Keywords: Special Education; Focus group; Family education.

\section{Introdução}

O desenvolvimento da linguagem tem se configurado em tema de preocupação de pesquisadores que se dedicam a investigar e desenvolver apoios, estratégias e recursos para a comunicação de pessoas com deficiência (FERREIRA, 2006; FERREIRA; DELIBERATO, 2008; DELIBERATO; MANZINI, 2012).

Nesse contexto, tomam parte programas terapêuticos e educacionais destinados a promover o envolvimento e a participação familiar de indivíduos com desordens da comunicação (FERREIRA, 2006; FERREIRA-DONATI; DELIBERATO, 2009; JONSSON, et. al., 2011; THUNBERG; CLAESSON, 2012; DELIBERATO et al., 2013). Essa relação complexa que se estabelece entre família e profissionais, compartilhando como foco de atençáo a criança ou jovem com deficiência, precisa ser cuidadosamente construída, num formato bidirecional e livre de papeis hierárquicos.

Nelson, Summers e Turnbull et al (2004), ao estudarem as relaçóes entre família e profissionais e suas implicaçôes na Educação Especial, realizaram uma pesquisa com 137 membros familiares e 53 profissionais, utilizando grupos focais e en- 
trevistas. $\mathrm{O}$ uso dos grupos focais permitiu compreender a visão dos participantes no tocante ao relacionamento entre pais e profissionais. Na primeira reuniâo do grupo, foram utilizadas questôes abertas para suscitar maior número de informações, e, na segunda, foi utilizado um roteiro com os temas que emergiram da discussão na reunião anterior. Os relatos foram gravados e transcritos para análise posterior. Segundo os autores, o trabalho possibilitou conhecer o ponto de vista dos pais quanto aos temas a partir da discussão gerada entre os membros do grupo.

Também estudando a parceria colaborativa entre família e profissionais, Blue-Banning e colaboradores (2004) conduziram 33 grupos focais com familiares de crianças sem e com deficiências, além de provedores e administradores de serviços relacionados. O grupo focal foi usado como primeiro método de coleta de dados para encorajar os participantes a trocar ideias e percepçóes a respeito do assunto tratado.

Vale ponderar, nesse contexto, que a expressão livre de opinióes, gerada pelas interaçôes em grupos de familiares, pode subsidiar a compilação de dados para a elaboração de programas de educação familiar que atendam efetivamente as necessidades e as expectativas desta populaçáo.

Em um artigo que buscou discutir a utilização das técnicas de grupo focal e análise de conteúdo em pesquisas com distúrbios do desenvolvimento, Silva e Assis (2010) reiteraram que

\begin{abstract}
a técnica de grupo focal possibilita o acolhimento do sujeito, devido à criação de um espaço para a expressão das angústias e ansiedades, esta aproximação valoriza os aspectos psicodinâmicos mobilizados na relação afetiva e direta com os participantes do estudo devido à escuta. Estes conteúdos latentes cheios de significados que organizam e estruturam o modo de vida das pessoas e suas relaçôes com os objetos poderão ser categorizadas por meio da analise de conteúdo. (SILVA; ASSIS, 2010, p. 146).
\end{abstract}

O Grupo Focal pode ser considerado como um método ou técnica de pesquisa qualitativa que permite ao pesquisador acessar percepçóes, atitudes ou opinióes que emergem da interação entre os indivíduos de um grupo, a respeito de um objeto ou tema comum e bem definido.

O campo das Ciências Humanas, assim como das Ciências da Saúde, vem se valendo da técnica do Grupo Focal em investigaçôes junto a diferentes grupos sociais, nas mais diversas temáticas. Pesquisas na área da reabilitação, da Educação e, mais especificamente, da Educação Especial têm relatado achados relevantes a partir da utilização de grupos focais (SVEZZIA; TRENCH, 2004; FERREIRA, 2006; PENTEADO et al., 2006; ALVES; SOBRINHO, 2014; TOLOI, 2015; FIORINI, 2015).

Para Morgan (1997), o grupo focal é uma forma de pesquisa qualitativa, com características próprias das entrevistas de grupo, porém, não no sentido da alternância entre as questōes do pesquisador e as respostas dos participantes. A ligação baseia-se na interação com o grupo, a partir da discussão de temas que são propostos pelo pesquisador, que tipicamente assume o papel de moderador. Um dos objetivos do grupo focal é definido por Gaskell (2004) como o de estimular os participantes a falar e a reagir àquilo que outras pessoas no grupo dizem. 
De modo bastante didático e interessante, Fern (2001) classificou os tipos de grupo focal em três modalidades: exploratórios, clínicos e vivenciais. Os grupos exploratórios - sobre o qual nos deteremos - estão centrados na produção de conteúdos. A sua orientaçáo teórica está voltada para a geração de hipóteses, o desenvolvimento de modelos e teorias, enquanto a prática tem como alvo a produçáo de novas ideias, a identificação das necessidades e expectativas e a descoberta de outros usos para um produto específico. Sua ênfase reside no plano intersubjetivo, ou melhor, naquilo que permite identificar aspectos comuns de um grupo alvo (FERN, 2001).

No estudo que descreveremos, o grupo focal foi o procedimento adotado para estruturar a dinâmica de um grupo de mães que teve por escopo a elaboração, por meio de uma avaliação sequencial, de fascículos de orientação em linguagem infantil ${ }^{1}$. Por ser a geraçáo de conteúdos, o aspecto principal da utilização dos grupos focais no estudo em questão, podemos identificar o design adotado como sendo de grupo exploratório. O objetivo do presente trabalho é apresentar as contribuições da técnica do grupo focal no processo de elaboração de fascículos de orientação familiar a respeito do desenvolvimento da linguagem de crianças com atrasos globais do desenvolvimento.

\section{Método}

Este estudo compõe uma pesquisa aprovada pelos Comitês de Ética em Pesquisa em Seres Humanos da APAE Bauru (Parecer n. 0012/2005-CEP) e da Faculdade de Filosofia e Ciências da UNESP de Marília (Parecer no 1071/2005).

\section{Critérios de seleção dos participantes - constituição do grupo focal}

Foram participantes da pesquisa e constituíram o grupo focal quatro mães de crianças com atrasos globais do desenvolvimento ${ }^{2}$, alunos da Educação Infantil de uma escola de Educação Especial do interior de São Paulo. As mães dos alunos das quatro salas de aula da Educação Infantil foram convidadas para participar. Para conferir representação às famílias dos alunos de todas as turmas, uma mãe de cada sala foi selecionada por meio de sorteio para integrar o grupo.

Antecedendo o sorteio, foram adotados como critérios de seleção: (1) indivíduos alfabetizados; (2) indivíduos que, quando devidamente convidados à participação na pesquisa, expressassem desejo em participar; (3) indivíduos que manifestassem ter tempo disponível para as reunióes.

Considerando que se tratava de avaliar fascículos escritos, foi desejável que os componentes do grupo focal tivessem diferentes graus de escolaridade, para que o texto das orientaçóes fosse compreensível a todos os participantes do Programa.

A caracterização dos participantes do grupo focal está descrita no Quadro 1. 
Quadro 1 - Caracterizaçấo das participantes do grupo focal em sua constituição inicial.

\begin{tabular}{|l|l|l|c|c|l|}
\hline Participante & \multicolumn{1}{|c|}{ Gênero } & $\begin{array}{c}\text { Sala de aula } \\
\text { representada }\end{array}$ & Idade & $\begin{array}{c}\text { Grau de } \\
\text { Escolaridade }\end{array}$ & \multicolumn{1}{|c|}{ Ocupaçáo } \\
\hline P1 & Feminino & Ed. Precoce II & 37 & $1^{\circ}$ grau completo & $\begin{array}{l}\text { Cabeleireira/ } \\
\text { Manicure }\end{array}$ \\
\hline P2 & Feminino & Pré I & 41 & $1^{\circ}$ grau completo & Do lar \\
\hline P3 & Feminino & Pré II & 27 & $2^{\circ}$ grau completo & Do lar \\
\hline P4 & Feminino & Ed. Precoce I & 26 & $2^{\circ}$ grau completo & Artesã \\
\hline
\end{tabular}

Fonte: Ferreira (2006).

Uma das pesquisadoras exerceu o papel de "moderador", com o papel de intermediar as discussóes e propiciar as condiçôes necessárias para que a troca de opinióes se desse satisfatoriamente com foco nos itens de discussão de interesse da pesquisa (MORGAN, 1997; GASKELL, 2004).

Atendendo às orientações da literatura, foi agregada ao grupo uma observadora, cujo papel, em suma, foi o de identificar comportamentos relevantes dos participantes, no que se referia ao padrão de participação nas discussôes ou às reaçôes não verbais à fala dos interlocutores (BLUE-BANNING et al., 2004; GALLAGHER et al., 2004). As observações eram anotadas em caderno específico para esse fim, seguidas de uma indicação do nome da participante e início ou abreviação do relato verbal.

\section{Elaboração e avaliação dos fascículos na dinâmica do grupo focal}

A primeira reuniáo do grupo focal teve as características de uma reunião instrutiva a respeito da dinâmica de trabalho que deveria ser seguida nas demais reunióes (ZEPELLINI, BONNAFÉ, PFEIFER, 1991; MORGAN, 1997; FERN, 2001).

As participantes foram orientadas quanto a: objetivo das reunióes, seus papéis na emissáo de opiniôes a respeito dos fascículos, e funçôes da observadora e da moderadora. Foram discutidas e combinadas algumas regras para dividir entre o grupo a responsabilidade de manter o fluxo da discussão (MORGAN, 1997; GONDIM, 2003). Ficou definido que: (1) não haveria falas simultâneas; (2) todas as pessoas deveriam participar livremente, inclusive interagindo umas com as outras; (3) não seriam desejadas conversas paralelas durante a discussão de um tópico. Ocasionalmente, as regras eram relembradas pela moderadora no início das reunióes.

Dando sequência à primeira, foram feitas mais sete reunióes presenciais, quinzenalmente, ao longo de quatro meses, nas quais foram discutidos aspectos de forma e conteúdo de cada um dos sete fascículos, para sua adequaçáo continuada. Vale informar que, paralelamente ao procedimento do grupo focal, os fascículos eram semanalmente enviados às famílias dos 38 alunos das classes de Educaçáo Infantil.

Após dois dias do envio de cada fascículo, realizava-se reuniáo para a avaliação do material informativo. A análise dos resultados da avaliação de cada fascículo resultava em reformulaçôes que se concretizavam na elaboração do fascículo seguinte. 


\section{Formas de registro}

Além do registro dos relatos verbais por meio de gravaçōes de áudio, a observadora buscou fazer registros abreviados dos relatos atrelados à expressão de comportamentos não verbais e da dinâmica do grupo, que pudessem enriquecer a transcrição e o tratamento dos dados (BLUE-BANNING et al., 2004; GALLAGHER et al., 2004). Isso permitiu agregar à transcrição comentários como: "risos", "concordou com a cabeça”, enriquecendo a amplitude dos dados.

Após a transcrição, os relatos foram organizados em caderno de conteúdo, configurando um quadro, cujas colunas seguiram a organizaçáo de categorias de análise. Segundo Tunes e Simão (1998), o caderno de conteúdo é um procedimento de coleta, análise e sistematização de relatos verbais.

\section{Local das reuniões}

As reuniôes foram realizadas na escola de Educação Especial frequentada pelos filhos das participantes. A sala das reuniôes tinha geometria hexagonal, era silenciosa e bem iluminada, com quatro janelas de maior dimensão vertical, acortinadas, o que permitia controle da entrada de luz natural, além da iluminação artificial.

O controle da luz do ambiente onde as reuniōes ocorrem é um importante aspecto a se considerar na utilização de métodos de entrevista ou interaçóes grupais, uma vez que a luminosidade obviamente interfere na percepção de minúcias de comportamentos não verbais, com destaque para as expressões faciais. Gatti (2005) e Manzini (2014) alertaram para a importância do arranjo ambiental e do local de realização das reuniôes de grupos focais.

A sala continha uma mesa redonda, com cinco cadeiras dispostas ao seu redor. Moderadora e participantes sentavam-se à mesa, de modo que a visualização entre todas fosse favorecida (MARINO, 2003). A observadora sentava-se numa cadeira próxima à mesa, posicionando-se estrategicamente para ter acesso visual a todas as participantes.

\section{A sequência de procedimentos das reuniões}

Cada reuniáo iniciava-se entre cinco a dez minutos após a chegada de todas as participantes. Nesse momento de recepção eram oferecidos sucos, água e biscoitos leves em uma mesa de apoio. Esse critério foi adotado na intenção de se respeitar o tempo de conversas informais, referentes a assuntos externos aos objetivos do grupo, e para propiciar um clima agradável e descontraído para o início da reunião.

O fascículo-alvo da discussão e o caderno de conteúdo eram dispostos sobre a mesa para permitir acesso às participantes. No início de cada reuniáo, a moderadora retomava as decisóes da reuniáo anterior e apresentava às participantes o caderno de conteúdo, cujas falas podiam ser facilmente identificadas em função de cores específicas atribuídas aos relatos de cada participante. Às participantes era permitido manusear, reler, discutir ou reafirmar aspectos de sua fala registrados no caderno de conteúdo. 
A condução das reuniōes seguiu um modelo semiestruturado, o que definiu o grau de envolvimento e interferência da moderadora. Foram previstos dois padróes de início das reunióes: partindo de consideraçôes gerais das participantes (que poderiam ocorrer naturalmente, sem interferência da moderadora) ou partindo de uma pergunta a respeito de aspectos gerais do fascículo-alvo feita pela moderadora.

A escolha por iniciar com questôes de aspectos gerais fundamenta-se na recomendação de Morgan (1997):

Há dois motivos para se iniciar no nível das generalidades. Primeiro, os participantes podem não estar prontos a seguir o pensamento detalhado do pesquisador sobre um tópico. Segundo, eles podem estar olhando em um sentido, e uma introdução detalhada pode levá-los a restringir o canal de discussão. (MORGAN, 1997, p.48).

Os relatos das duas primeiras reunióes do grupo focal permitiram concluir a definição das categorias de análise do caderno de conteúdo, que, complementarmente ao roteiro, serviram de base para a condução das reunióes.

A discussão seguia a ordem de surgimento dos tópicos, de modo flexível. Buscou-se enfatizar os tópicos relacionados ao conteúdo, de modo que se pudesse identificar a compreensão das mães a respeito das informaçóes do fascículo e as relaçóes que haviam feito com experiências práticas.

Durante os relatos das participantes, a moderadora fazia intervenções orais, com "ahâ", "hum", "sei", e repetia os finais das frases, com a finalidade de demonstrar atenção, estimular a continuidade do relato e confirmá-lo.

Antes de finalizar a reunião, as participantes eram estimuladas a acrescentar opiniōes. Em seguida, a moderadora fazia um resumo oral das discussôes, destacando as principais sugestóes de adequação para o próximo fascículo, para que as participantes pudessem confirmar ou corrigir as informaçóes. Na despedida, a moderadora fazia um agradecimento às mães e as lembrava da data da próxima reunião.

Imediatamente após a finalização da reunião, moderadora e observadora discutiam elementos contextuais, como o clima geral da reunião e detalhes atinentes à participação das mães (GALLAGHER et al., 2004).

\section{Análise dos dados}

Os registros dos relatos verbais obtidos nas reunióes do grupo focal foram transcritos na íntegra, seguindo as normas de Marcuschi (1986) e outras convençóes definidas pelas próprias pesquisadoras, como: (risos), quando a participante sorria; (dois pontos) quando a participante ia explicar seu relato imediatamente anterior; (concordou com a cabeça), quando uma participante balançava a cabeça em sinal de concordância, etc. $\mathrm{O}$ uso de tais informaçôes na transcrição dos relatos só se tornou possível pelo registro de observação empreendido durante as reuniôes.

Para que se pudesse identificar a fala de cada participante, foi atribuída uma cor de fonte para cada uma delas, seguida de uma codificação: $\mathrm{M}$ (moderadora), P1 (participante 1), P2 (participante 2), P3 (participante 3) e P4 (participante 4). 
Após a transcrição, a gravação era ouvida novamente pela pesquisadora, acompanhando, então, o registro escrito, como procedimento de validação intra-observador. Isso feito, as informaçóes verbais eram transportadas para o caderno de conteúdo. Essa sequência de procedimentos conferia à avaliação dos fascículos uma característica processual, com base numa prática colaborativa entre família e profissional.

A utilização do caderno de conteúdo garante ao sujeito da pesquisa exercer o papel de participante, na medida em que, posteriormente ao seu relato, tem acesso à sua fala representada e pode operar sobre o fenômeno consciente por meio de novos relatos. De acordo com Tunes e Simão (1998), o pesquisador, por sua vez, utiliza a análise do relato verbal para planejar o prosseguimento da pesquisa, visando atingir sua meta, que se refere a processos subjetivos do participante.

As subcategorias do caderno de conteúdo foram, em relação ao "Conteúdo": (1) Etiologia; (2) Recursos e estratégias de comunicação; (3) Habilidades comunicativas; (4) Informaçôes teóricas a respeito da linguagem; (5) Interlocutores; (6) Funçốes e habilidades relacionadas à linguagem; e (7) Impressóes/Observaçôes gerais.

No que se refere à análise de "Forma", foram definidas as seguintes categorias e subcategorias: "texto", com as subcategorias "letra", "quantidade/volume" (de texto) e "disposição/orientação" (do texto); "ilustraçóes" e "cor da folha".

Além das categorias mencionadas, foi acrescida a categoria "leitores", que servia aos relatos referentes às pessoas que haviam lido os fascículos.

\section{Resultados e discussão}

O tempo de duração das reuniôes variou entre 22 e 46 minutos (Quadro 2). A frequência das participantes às reunióes foi variável. As ausências ocorreram em virtude de doenças dos filhos. É importante fazer constar que na $5^{\text {a }}$ reuniáo P2 manifestou desistência, e na $7^{\text {a }}$ reunião, a participante P3 também desistiu, alegando impossibilidade de locomover-se até o local das reuniôes. Apesar dos esforços engendrados para recrutar novos participantes, não obtivemos sucesso. Todas as pessoas contatadas alegavam não poder participar por não terem com quem deixar outros filhos ou por não poderem faltar ao trabalho. 
Quadro 2 - Informaçóes a respeito das reunióes do grupo focal.

\begin{tabular}{|c|c|c|c|}
\hline REUNIĀO & DURAÇĀO & $\begin{array}{l}\text { PARTICIPANTES } \\
\text { PRESENTES }\end{array}$ & ATIVIDADE \\
\hline 1a Reunião & $45 \mathrm{~min}$. & P1; P2; P3 e P4 & Reunião instrutiva \\
\hline 2a Reuniáo & $22 \mathrm{~min}$. & P1; P2 e P3 & Avaliaçấo do Fascículo 1 \\
\hline $3^{\text {a Reuniáo }}$ & $45 \mathrm{~min}$. & P1; P3 e P4 & Avaliaçăo do Fascículo 2 \\
\hline 4a Reuniáo & $46 \mathrm{~min}$. & P1; P3 e P4 & Avaliaçáo do Fascículo 3 \\
\hline $5^{\text {a Reuniáo }}$ & $39 \mathrm{~min}$. & P1 e P3 & Avaliaçấo do Fascículo 4 \\
\hline 6a Reuniáo & $27 \mathrm{~min}$. & P1; P3 e P4 & Avaliaçăo do Fascículo 5 \\
\hline $7^{\text {a Reuniáo }}$ & $27 \mathrm{~min}$. & P1 e P4 & Avaliaçáo do Fascículo 6 \\
\hline $8^{\mathrm{a}}$ Reuniăo & $23 \mathrm{~min}$. & P1 e P4 & Avaliaçáo do Fascículo 7 \\
\hline
\end{tabular}

Legenda: P1 - participante 1; P2 - participante 2; P3 - participante 3; P4 - participante 4.

Fonte: Ferreira (2006).

Na segunda reunião do grupo focal, quando se procedeu à análise do Fascículo 1, pôde-se observar uma dificuldade em se manter o tópico de discussão.

$\mathrm{Na}$ terceira e quarta reunióes, foi possível perceber a necessidade das participantes em definir a identidade do grupo, o que pode ser exemplificado pelo relato da participante P4:

O meu logotipo foi formado, né, porque ficou um logotipo (risos). (P4).

$\mathrm{Na}$ quarta reuniáo, ficou evidente a utilização do fascículo por outros familiares, conforme se observa no relato da participante P4:

Olha... eu nunca vi o E. se interessando por nada de ler... Ele está gostando bastante porque ele chega, na hora em que ele vê o fascículo, ele já pega e já quer ler. Antes, no primeiro, eu deixei em cima da mesa. No segundo eu deixei dentro da bolsa. Eu falei: "ele vai procurar"... aí ele achou... (risos). (P4).

Além disso, aplicaçôes práticas das orientações foram relatadas, como é possível constatar nos relatos das participantes P2 e P4:

$\mathrm{Eu}$ achei que melhorou bastante em casa, no relacionamento assim da fala com ela. Porque eu não tinha... realmente, como a P1 falou, a paciência, até mesmo de você ficar olhando. "Vamos conversar, vamos. Entáo, olha pra mim”. Sentar com ela e perceber o olhar dela comigo, né? Isso foi muito importante pra mim. (P2).

Agora por causa dos fascículos, pra comunicação, ele (o marido) está esperando o E. falar porque ele não esperava. (P4).

A respeito do volume e do tipo das informaçóes veiculadas pelo fascículo, os relatos de duas participantes (P2 e P4) evidenciaram percepção quanto ao tipo de informaçôes da parte "Dicas de linguagem", que continha orientaçôes relacionadas a 
"como fazer", fornecendo recomendaçóes curtas e de natureza prática para aplicação de alguma estratégia de estimulaçáo de linguagem no cotidiano familiar.

Pra mim, das dicas está melhor... A gente vai nas dicas mesmo, realmente a gente vai naquilo que é mais prático. (P2).

Eu acho ainda que têm pessoas que não têm muito costume de ler... Na hora em que pega o fascículo, acaba indo direto nas dicas. Eu vou ver o que eu posso fazer pelo meu filho. (P4).

$\mathrm{Na}$ quinta reunião, foi possível perceber uma efusão de relatos pertinentes às habilidades de comunicação dos filhos das participantes e ao comportamento de outros membros de suas famílias frente às manifestaçôes expressivas das crianças. $\mathrm{O}$ relato de P3 é apresentado como exemplo:

Então, a gente está começando a conversar, mas até minha mãe, que não era muito sabe assim, ela está explicando mais... Que nem televisão, quando é notícia de uma coisa, ela sabe que a minha mãe gosta, começa o jornal e a minha mãe, às vezes está na cozinha, ela corre e fala: "Vovó, unal, unal". Quer dizer: o jornal começou... [...] fora que era só eu que conversava com ela... Agora está todo mundo, no geral. E meu sobrinho está vendo, até minha irmã está mudando com ele... Assim: está conversando mais... Então, até a gente assim, família no geral está melhorando... Está tendo mais diálogo... (P3).

$\mathrm{Na}$ análise do Fascículo 5, as participantes se expressaram quanto à orientação a respeito de quem pode ajudar no desenvolvimento da comunicação da criança:

[...] Então, para as pessoas que estão recebendo, é bom porque às vezes as pessoas não têm tempo de brincar... às vezes deixa a criança no cantinho, não dá muita importância no que eles falam. E com esses aqui vai, de novo, né, aquele puxãozinho de orelha que cada fascículo leva... assim: "Preste atenção nesse ponto", e aqui está dizendo que não é só o pai e a mãe, é qualquer pessoa em qualquer situação. Então, eu achei que ficou bem claro isso aqui. (P3).

Um exemplo de aplicação da orientação a respeito dos cuidados quanto ao modo de apresentaçáo da fala para a criança pode ser identificado no relato da participante P3:

Diminuir a quantidade de informação que eu estou passando pra ela. Entấo, está ficando muito mais fácil, ela está entendendo bem melhor. (P3).

A percepção das mães a respeito das capacidades expressivas dos seus filhos também pôde ser acessada nessa reunião, conforme expresso pelo seguinte exemplo de fala:

[...] Chegou em casa ontem assim (fazendo movimento de atrito com as duas mãos), aí eu perguntei para a professora, né, ela disse: "Ah, é que a gente cantou uma musiquinha e tinha que lavar roupa...". Então, atém com eles na escolinha, a gente acaba aprendendo e tudo o que ela vê fora de casa, quando chega em casa ela quer 
mostrar. Às vezes, a gente não entende, ela fica brava ou desiste... aí depois ela vê que não entendeu, então, ela volta e tenta fazer de novo [...] a gente dava importância para o que ela falava. Agora não, a gente está dando importância no que ela está fazendo. (P3).

Também foi possível notar a diminuição de sugestôes quanto à forma dos fascículos, o que fica evidente no relato da participante P4:

Eu acredito assim... que as mudanças que tinham que ser feitas já foram feitas. [...] Agora, em relação à letra, ao formato, à organização das informaçôes, pra mim está excelente. (P4).

Quanto às orientaçóes do Fascículo 7, as participantes avaliaram como sendo relacionadas a atividades práticas, comuns de seus cotidianos, como demonstrado no relato da participante $\mathrm{P} 4$ :

Em relação aos Fascículos 6 e 7, as dicas são muito mais do nosso dia-a-dia. (P4).

Quanto à orientação a respeito de leitura, as manifestações de compreensão foram positivas, como ilustra o relato a seguir:

A criança tem que aprender não só ouvindo a gente, mas vendo as figuras também. O P. tem mania de seguir com o dedinho. Eu leio livros sem figuras. Ele vai seguindo com o dedinho. E a criança vai tendo noção de letra. (P1).

Houve manifestação positiva a respeito das fotografias do Fascículo 7, que ilustram atividades das mães com seus filhos. A participante P4 retomou a avaliação do Fascículo 6, citando a figura de uma criança na cadeira de rodas jogando basquete.

Eu amei as fotos que saíram das atividades. [...] Começou cru, aí foi indo, foi indo... Por quê náo colocar as figuras da prática no final? [...] Que nem a figura do Fascículo 6, do menino jogando basquete na cadeira. Pra mim, foi uma coisa maravilhosa porque... chama mesmo a atenção, independente de estar ou não numa cadeira, pra deficiência. Pra mim, foi excelente. Achei que ficou uma figura bem do nosso dia-a-dia, bem real, próxima da gente. E em relaçáo à fotografia, é o que a P1 falou: a máe está vendo o que uma outra mãe está fazendo, brincando, estimulando o filho. (P4).

No decorrer da reunião, e, principalmente, nos minutos finais, as participantes se manifestaram quanto ao programa de educação familiar, com relação aos benefícios percebidos e ao processo de elaboração dos fascículos de orientação. Os relatos seguintes exemplificam tal constataçáo:

Eu espero que eles (os pais) tenham acompanhado todos os fascículos porque deu pra aproveitar muito. [...] Quem analisar vai ver: começou com todas as informaçóes e no final a gente colocando em prática as orientaçóes que a gente recebeu. (P4).

Às vezes a gente pega até muita dica que as pessoas passam pra gente... em papel mesmo, por escrito, que tem tantas palavras que a gente não sabe nem da onde vem, se é de comer, se é de beber, que você acaba náo aproveitando nada. Aqui, as dicas são realmente 
do dia-a-dia. A forma de passar é uma forma direta, simples. Tem muita pessoa que é crua, como a gente falou tem muita gente que não sabe nem ler, mas não tem como ter dúvida de como praticar aquela dica. Está bem direto. (P4).

Os fascículos do programa de educação familiar podem ser definidos como instrumento de coleta de dados e como objeto-resultado do processo de adequaçáo do programa. Isso se dá, considerando que cada fascículo era apresentado como resultado da reunião anterior e concomitantemente, submetido à avaliação para adequação.

Essa lógica procedimental conferiu dinamismo ao processo de elaboração dos fascículos, numa ação afirmativa dos princípios propostos por Kaiser (1999) a respeito da interação entre pais e profissionais:

\begin{abstract}
A interação deve ser bidirecional (pais e profissionais trocam informações), transacional (pais e profissionais são afetados e modificam seu comportamento mutuamente pela expressão do outro), e ambos devem compartilhar objetivos e o mesmo foco de atenção (os objetivos e o foco são definidos pelo pai e pelo profissional no início da interação e pode mudar no seu curso). (KAISER et al., 1999, p. 2).
\end{abstract}

Os estilos de moderação semidiretivo e, algumas vezes, diretivo, utilizados nas discussóes do grupo focal e anteriormente relatados em trabalho da mesma natureza (ZEPELLINI et al, 1991; SCHIEFER et al, 1992; GALVANI et al., 2001; GIVIGI, 2005; FIORINI, 2015) se mostraram adequados para permitir o fluxo das discussóes e suscitar expressão de opinióes específicas a respeito dos fascículos de orientação.

\title{
Considerações finais
}

Os relatos das participantes do grupo focal indicaram que as orientaçóes foram compreendidas, em sua maioria, e postas em prática nas atividades diárias com seus filhos, resultados observados também nos trabalhos de Galvani et al (2001), Oliveira (2002) e Givigi (2005).

O grupo focal se mostrou como procedimento adequado para envolver os pais num exercício reflexivo a respeito do desenvolvimento da comunicação e para definir os conteúdos e o formato de orientaçóes escritas para a população-alvo. Os resultados indicaram que a elaboração dos fascículos, em parceria com as famílias, oportunizou aos pais ampliar a participação no desenvolvimento da linguagem de seus filhos.

Assim como abordado por Omote (2003), um sentimento de competência em relaçáo ao papel desempenhado no desenvolvimento da comunicação de seus filhos pôde ser percebido nos relatos das mães nas últimas reunióes do grupo focal.

Vale considerar, por fim, que as dificuldades percebidas na promoção de frequência dos participantes a todas as reuniôes nos alerta para as peculiaridades da utilização de grupos focais em pesquisas qualitativas. A conjugação da disponibilidade de horários, deslocamento e motivação pessoal de diferentes indivíduos para constituir um grupo é tarefa árdua, cuja complexidade deve ser considerada seriamente pelo pesquisador na fase de delineamento do estudo. 


\section{Referências}

ALVES, E. P; SOBRINHO, R.C. Escolarização de alunos com deficiência e as inter-relaçôes família, escola e gestores públicos da educaçáo especial. Revista Educaçáo Especial, v. 27, n. 48, p. 171-184, 2014.

BLUE-BANNING, M. et al. Dimensions of family and professional partnerships: constructive guidelines for collaboration. Council for Exceptional Children, v. 70, n. 2, p. 167-184, 2004.

DELIBERATO, D.; MANZINI, E. J. Identification of the communicative abilities of Brazilian children with cerebral palsy in the family context. Communication Disorders Quarterly, v. 33, n. 4, p. 95-20, 2012.

DELIBERATO, D.; MANZINI, E. J.; MASSARO, M.; GOLDONI, N.; SILVEIRA, J. M. V. Programa de capacitação de famílias de crianças, jovens e adultos usuários de comunicação alternativa. Informática na educaçáo: teoria \& prática, Porto Alegre, v. 16, n. 2, p. 89-103, jul./dez. 2013.

FERN, E. F. Advanced focus group research. London: Sage Publications, 2001.

FERREIRA, G. C. Programa de educaçáo familiar continuada em linguagem: orientaçôes a pais de crianças com atrasos globais do desenvolvimento. 2006. 165f. Dissertaçáo (Mestrado em Educaçáo) - Departamento de Educação Especial, Faculdade de Filosofia e Ciências da UNESP de Marília, Marília, 2006.

FERREIRA, G. C.; DELIBERATO, D. Análise de guias de orientação para pais a respeito da linguagem infantil. In: ALMEIDA, M. A.; MENDES, E. G.; HAYASHI, M. C. P. I. (Eds.) Temas em Educaçáo Especial: múltiplos olhares. Araraquara: Junqueira \& Marin Editores; Brasília, D.F.: CAPES-PROESP, 2008. pp 301-310.

FERREIRA-DONATI, G. C.; DELIBERATO, D. Programa de educação familiar continuada em linguagem: contribuiçôes de orientaçóes escritas num modelo de educaçáo à distância. In: DELIBERATO, D.; GONÇALVES, M. J.; MACEDO, E. C. (Orgs.) Comunicação alternativa: teoria, prática, tecnologias e pesquisa. São Paulo: Memnon Ediçóes Científicas, 2009. pp. 302-310.

FIORINI, M. L. S. Formaçáo continuada do professor de educaçáo física em tecnologia assistiva visando a inclusão. 2015. 155f. Tese (Doutorado em Educação) Departamento de Educaçáo Especial, Faculdade de Filosofia e Ciências da UNESP de Marília, Marília, 2015.

GALLAGHER, P. A.; RHODES, C. A.; DARLING, S. M. Parents as professionals in early intervention: a parent educator model. Topics in early childhood special education, v. 24, n. 1, p. 5-13, 2004.

GALVANI, C. et al. Projeto Ação Conjunta: a importância do trabalho com grupo de famílias de portadores de deficiência mental para a inclusão social. Temas sobre desenvolvimento, v. 10, n. 57, p. 45-48, 2001.

GASKELL, G. Entrevistas individuais e grupais. In: BAUER, M. W.; GASKELL, G. (editores). Pesquisa qualitativa com texto, imagem e som: um manual prático. 3. ed. Petrópolis: Vozes, 2004. cap. 3, p. 64-89. (Tradução de Pedrinho A. Guareschi).

GATTI, A. B. Grupo focal na pesquisa em ciências sociais e humanas. Brasília, D.F.: Líber, 2005. (Série Pesquisa em Educação, v. 10).

GIVIGI, R. C. N. A mediaçấo fonoaudiológica na interlocuçáo entre pais e filhos com dificuldade de linguagem e comunicação. In: I Congresso Brasileiro de Comunicaçáo Alternativa e I Congresso Internacional de Linguagem e Comunicação da pessoa com deficiência, 2005, Rio de Janeiro. Programa e resumos dos trabalhos. Rio de Janeiro: [s.n.], 2005. p.24.

GONDIM, S. M. G. Grupos focais como técnica de investigação qualitativa: desafios metodológicos. Paidéia, v. 12, n. 24, p. 149-161, 2003.

JONSSON, A.; KRISTOFFERSSON, L.; FERM, U.; THUNBERG, G. The ComAlong Communication Boards: Parents' Use and Experiences of Aided Language Stimulation. Augmentative and Alternative Communication, v. 27, n. 2, p. 103-116, 2011.

KAISER, A. et al. Rejoinder: toward a contemporary vision of parent education. Topics in early childhood special education, v. 19, n. 3, p. 173-6, 1999.

NELSON, L. G. L.; SUMMERS, J. A.; TURNBULL, A. P. Boundaries in family-professional relationships: implications for special education. Remedial and special education, v. 25, n. 3, p. 153-165, 2004.

MARCUSCHI, L. A. Análise da conversaçáo. São Paulo: Ática, 1986.

MANZINI. E. J. Consideraçôes sobre elaboração de roteiros para grupo focal. In: NUNES, L. R. O. P. Novas trilhas no modo de fazer pesquisa em Educação Especial. São Carlos: Marquezine \& Manzini: ABPEE, 2014. p.127-139. 
MARINO, E. Manual de avaliaçáo de projetos sociais. São Paulo: Saraiva: Intituto Ayrton Senna, 2003.

MORGAN, D. L. Focus group as qualitative research. Newbury Park, CA: Sage Publications, 1997.

OLIVEIRA, C. M. C. Grupo de orientação aos familiares de crianças com gagueira. Jornal Brasileiro de Fonoaudiologia, Curitiba, v. 3, n.12, p.198-203, 2002.

OMOTE, S. Introdução: a deficiência e a família. In: MARQUEZINE, M. C. et al. (Org.) O papel da família junto ao portador de necessidades especiais. Londrina: Eduel, 2003, p. xv-xviii.

PENTEADO, R. Z.; GONÇALVES, C. G. O; SILVÉRIO, K. C. A.; ROSSI, D.; LIBARDI, A.; VIEIRA, T. P. G. Grupos focais: possibilidades e aplicaçôes para as pesquisas e práticas fonoaudiológicas. Revista da Sociedade Brasileira de Fonoaudiologia, v. 11, n. 2, p.124-8, 2006.

SCHIEFER, A. M.; CHIARI, B. M.; BARBOSA, L. M. G. Orientação aos pais: uma proposta de atuação preventiva na fala de crianças disfluentes. Pró-fono revista de atualizaçáo científica, v. 4, n.1, p. 3-6, 1992.

SILVA, J. R. S.; ASSIS, S. M. B. Grupo focal e análise de conteúdo como estratégia metodológica clínicaqualitativa em pesquisas nos distúrbios do desenvolvimento. Cadernos de Pós-Graduaçáo em Distúrbios do Desenvolvimento, São Paulo, v.10, n.1, p.146-152, 2010.

SVEZZIA, S. L.; TRENCH, B. Admirável lugar no mundo de velhos: práticas e vivências fonoaudiológicas em hospitais. Saúde e Sociedade v.13, n.3, p.78-91, set-dez 2004.

THUNBERG, G.; CLAESSON, B. ComYoung: a course for parents of school-aged children in need of AAC. Conference Proceedings of 15th Biennial Conference of the International Society for Augmentative and Alternative Communication, Pittsburgh, PA, 2012.

TOLOI, G. G. Formação de professores de educação física para inclusão educacional usando tecnologia assistiva. 2015. 212f. Tese (Doutorado em Educação) Departamento de Educação Especial, Faculdade de Filosofia e Ciências da UNESP de Marília, Marília, 2015.

TUNES, E.; SIMÃO, L. M. Sobre análise do relato verbal. Psicologia USP, São Paulo, v. 9, n. 1, p. 303-324, 1998.

ZEPELLINI, S. L.; BONNAFÉ, M. C.; PFEIFER, E. Projeto "Orientação à família da pessoa portadora de deficiência auditiva”. Pró-fono revista de atualizaçáo científica, v. 3, n. 1, p. 13-18, 1991.

\section{Notas}

${ }^{1}$ Esse estudo foi realizado como parte dos procedimentos de uma pesquisa de mestrado, intitulada "Programa de Educação Familiar Continuada em Linguagem: orientaçôes a pais de crianças com atrasos globais do desenvolvimento" (FERREIRA, 2006). Os fascículos de orientação mencionados ao longo do texto figuram como apêndices na dissertação de mestrado.

${ }^{2}$ Consideremos a concepção de atraso global do desenvolvimento no contexto das instituições de Educação Especial como sendo uma condição na qual mais de uma área do desenvolvimento, envolvendo as competências cognitivas, linguísticas, motoras e afetivas, estejam atrasadas em seu ritmo evolutivo, comparando-se à norma.

\section{Correspondência}

Débora Deliberato - Universidade Estadual Paulista Júlio de Mesquita Filho, Faculdade de Filosofia e Ciências. Rua: Hygino Muzzi Filho, 737. CEP: 17525-900. Marilia, São Paulo, Brasil.

E-mail: gracecf@uol.com.br - delibera@marilia.unesp.br

Recebido em 26 de julho de 2015

Aprovado em 15 de junho de 2016 